\title{
Colletotrichum siamense causing anthracnose-twister disease of onion (Allium cepa) in Sri Lanka
}

\author{
Indunil S. Herath ${ }^{1} \cdot$ Dhanushka Udayanga $^{1}$ (D) Shaneya Miriyagalla ${ }^{1} \cdot$ Lisa A. Castlebury $^{2} \cdot$ Dimuthu S. Manamgoda $^{3}$
}

Received: 22 August 2021 / Accepted: 26 October 2021 / Published online: 1 November 2021

(c) Australasian Plant Pathology Society Inc. 2021

\begin{abstract}
Symptomatic samples of anthracnose-twister disease of cultivated onion (Allium cepa) were collected from heavily infected fields at Matale district, Sri Lanka during a severe outbreak that occurred through late July to August in 2020. The pathogen was identified as Colletotrichum siamense based on morphology and combined gene sequence analysis of nuclear ribosomal internal transcribed spacers 1 and 2 with 5.8S region (ITS), glyceraldehyde-3-phosphate dehydrogenase gene (GPDH) and beta-tubulin (TUB) regions. $C$. siamense is a species with global distribution and a wide host range. This is the first report of $C$. siamense infecting onion in Sri Lanka.
\end{abstract}

Keywords Anthracnose $\cdot$ Molecular diagnostics $\cdot$ Onion diseases $\cdot$ Tropical pathogens

Onion (Allium cepa), an important crop grown for its flavorful bulbs and leaves, is consumed globally. Large scale cultivation of onion in Sri Lanka accelerated in the early 1980's. Overall, the extent of cultivation has increased since then with some annual fluctuations. However, in the year 2020 local cultivation did not meet even a quarter of the annual requirement of onion (DCS, 2020). One major factor contributing towards the reduction of onion yield in the country was the impact of plant diseases that occur both in the nurseries and field. Fungal pathogens are the causative agents of many severe diseases that reduce yield of onion worldwide. Among them, species of Alternaria, Colletotrichum, Fusarium, Sclerotium, and Rhizoctonia are widely encountered (Conn et al. 2012; Mishra et al. 2014).

Among the major onion producing regions in Sri Lanka, Matale district produces an estimated 50\% of the total

Dhanushka Udayanga

dudayanga@sjp.ac.lk

1 Department of Biosystems Technology, Faculty of Technology, University of Sri Jayewardenepura, Pitipana, Homagama 10200, Sri Lanka

2 Mycology and Nematology Genetic Diversity and Biology Laboratory, United States Department of Agriculture Agricultural Research Service, MD 20705 Beltsville, USA

3 Department of Botany, Faculty of Applied Sciences, University of Sri Jayewardenepura, Nugegoda 10250, Sri Lanka production of big onion (DCS, 2020). Through late July to August in 2020, a severe outbreak of anthracnose-twister disease was reported from several localities of onion cultivations of Matale district (Central Province), in Sri Lanka leading to a significant yield loss. These affected onion fields in Matale district were reported to abandon because of this disease, causing a short-term scarcity of onion supply in the local market. The leaves and bulbs of onion plants showed typical anthracnose-twister disease symptoms (Alberto et al. 2019), such as yellow to dark spots of leaves and bulbs, irregular leaf yellowing, curling, twisting, chlorosis, abnormal elongation of the neck, formation of slender bulbs and ultimately the death of plants. Concentric rings of acervuli and orange conidial masses were abundantly observed on bulbs with anthracnose symptoms and twisted leaves of diseased plants.

Multiple samples of infected onion plants with disease symptoms were collected from heavily infected fields in Bulanawewa, Galewela (7.84 N, 80.58E) and Sigiriya area (7.95 N, 80.75E) in Matale District. The single spore isolation method (Choi et al. 1999) was used to obtain the pathogen from diseased plant tissue onto Potato Dextrose Agar (PDA) plates. The inoculated plates were incubated at $25{ }^{\circ} \mathrm{C}$ under dark conditions. Characteristics of conidia, conidiophores, and appressoria were assessed under a Carl Zeiss compound light microscope, using an Axiocam digital camera. (Carl Zeiss Microscopy, Thornwood, NY, USA). In total, 10 isolates were obtained from the infected 
samples and all the isolates were morphologically identical. Two representative pure cultures of the pathogen were deposited at University of Sri Jayewardenepura culture collection (USJCC) under the accessions USJCC-0056 and USJCC- 0058.

DNA was extracted from two isolates grown on PDA at $25{ }^{\circ} \mathrm{C}$ for $7 \mathrm{~d}$ using a modified protocol of Arnold and Lutzoni, (2007). The ribosomal internal transcribed spacer (ITS) region was amplified using the primer pairs,
ITS-1/ITS-4 (White et al. 1990) and Sanger sequenced by Macrogen, Korea. To confirm the identity of the pathogen in Colletotrichum gloeosporioides complex, the glyceraldehyde-3-phosphate dehydrogenase (GPDH) and beta-tubulin (TUB2) gene regions were amplified using the primer pairs, GDF1/GDR1 (Templeton et al. 1992) and $\mathrm{T} 1 / \mathrm{Bt}-2 \mathrm{~b}$ (O'Donnell and Cigelnik 1997) respectively, following the methods described by Damm et al. (2009). Samples were Sanger sequenced using the same

Table 1 Isolates of Colletotrichum species used in the phylogenetic analyses with details of host and location, and GenBank accession numbers of the sequences

\begin{tabular}{|c|c|c|c|c|c|c|}
\hline \multirow[t]{2}{*}{ Species } & \multirow[t]{2}{*}{ Isolate code/Culture collection } & \multirow[t]{2}{*}{ Host } & \multirow[t]{2}{*}{ Country } & \multicolumn{3}{|c|}{ GenBank accessions } \\
\hline & & & & ITS & GPDH & TUB2 \\
\hline C. aenigma & ICMP $18608^{\mathrm{T}}$ & Persea americana & Israel & JX010244 & JX010044 & JX010389 \\
\hline C. aeschynomenes & ICMP 17673, ATCC $201874^{\mathrm{T}}$ & Aeschynomene virginica & USA & JX010176 & JX009930 & JX010392 \\
\hline C. alatae & CBS 304.67, ICMP $17919^{\mathrm{T}}$ & Dioscorea alata & India & JX010190 & JX009990 & JX010383 \\
\hline C. alienum & ICMP $12071^{\mathrm{T}}$ & Malus domestica & New Zealand & JX010251 & JX010028 & JX010411 \\
\hline C. aotearoa & ICMP 18537 & Coprosma sp. & New Zealand & JX010205 & JX010005 & JX010420 \\
\hline C. asianum & ICMP 18580, CBS $130418^{\mathrm{T}}$ & Coffea arabica & Thailand & FJ972612 & JX010053 & JX010406 \\
\hline C. boninense & CBS 123755 , MAFF $305972^{\mathrm{T}}$ & Crinum asiaticum var. sinicum & Japan & JQ005153 & JQ005240 & JQ005588 \\
\hline C. camelliae & CGMCC 3.14925 T, LC1364 & Camellia sinensis & China & KJ955081 & KJ954782 & KJ955230 \\
\hline C. clidemiae & ICMP $18658 \mathrm{~T}$ & Clidemia hirta & USA, Hawaii & JX010265 & JX009989 & JX010438 \\
\hline C. cordylinicola & $\underset{\mathrm{T}}{\mathrm{MFLUCC}}$ 090551, ICMP18579 & Cordyline fruticosa & Thailand & JX010226 & JX009975 & JX010440 \\
\hline C. fructicola & ICMP 18581, CBS $130416^{\mathrm{T}}$ & Coffea arabica & Thailand & JX010165 & JX010033 & JX010405 \\
\hline C. gloeosporioides & $\begin{array}{l}\text { IMI } 356878 \text {, ICMP } 17821 \text {, } \\
\text { CBS } 112999 \text { T }\end{array}$ & Citrus sinensis & Italy & JX010152 & JX010056 & JX010445 \\
\hline C. horii & ICMP 10492 T, MTCC 10841 & Diospyros kaki & Japan & GQ329690 & GQ329681 & JX010450 \\
\hline C. kahawae subsp. kahawae & IMI 319418 T, ICMP 17816 & Coffea arabica & Kenya & JX010231 & JX010012 & JX010444 \\
\hline C. musae & $\begin{array}{l}\text { CBS } 116870 \text { T, ICMP } 19119 \text {, } \\
\text { MTCC } 11349\end{array}$ & Musa sp. & USA & JX010146 & JX010050 & HQ596280 \\
\hline C. nupharicola & CBS 470.96, ICMP $18187^{\mathrm{T}}$ & Nuphar lutea subsp. polysepala & USA & JX010187 & JX009972 & JX010398 \\
\hline C. psidii & CBS 145.29, ICMP $19120^{\mathrm{T}}$ & Psidium sp. & Italy & JX010219 & JX009967 & JX010443 \\
\hline C. queenslandicum & ICMP $1778^{\mathrm{T}}$ & Carica papaya & Australia & JX010276 & JX009934 & JX010414 \\
\hline C. salsolae & ICMP $19051^{\mathrm{T}}$ & Salsola tragus & Hungary & JX010242 & JX009916 & JX010403 \\
\hline \multirow[t]{3}{*}{ C. siamense } & ICMP 18578, CBS $130417^{\mathrm{T}}$ & Coffea arabica & Thailand & JX010171 & JX009924 & JX010404 \\
\hline & USJCC 0056 (C6) & Allium cepa & Sri Lanka & MW440478 & MZ803133 & MZ803137 \\
\hline & USJCC 0058 (C10) & Allium сера & Sri Lanka & MW444844 & MZ803135 & MZ803138 \\
\hline C. syzygicola & DNCL021 MFLUCC $100624^{\mathrm{T}}$ & Syzygium samarangense & Thailand & KF242094 & KF242156 & KF254880 \\
\hline C. theobromicola & $\begin{array}{l}\text { MTCC } 11350, \text { CBS } 124945^{\mathrm{T}} \text {, } \\
\text { ICMP } 18649\end{array}$ & Theobroma cacao & Panama & JX010294 & JX010006 & JX010447 \\
\hline C. $t i$ & ICMP $4832^{\mathrm{T}}$ & Cordyline sp. & New Zealand & JX010269 & JX009952 & JX010442 \\
\hline C. tropicale & $\begin{array}{l}\text { CBS } 124949, \text { ICMP } 18653 \text {, } \\
\text { MTCC } 11371^{\mathrm{T}}\end{array}$ & Theobroma cacao & Panama & JX010264 & JX010007 & JX010407 \\
\hline C. xanthorrhoeae & $\begin{array}{l}\text { BRIP 45094, ICMP 17903, } \\
\text { CBS } 127831^{\mathrm{T}}\end{array}$ & Xanthorrhoea preissii & Australia & JX010261 & JX009927 & JX010448 \\
\hline
\end{tabular}

ATCC American Type Culture Collection, BRIP Queensland Plant Pathology Herbarium, Australia, CBS-Westerdijk Fungal Biodiversity Institute, Utrecht, The Netherlands, CGMCC-China, General Microbiological Culture Collection, Beijing, China, ICMP-International Collection of Microorganisms from Plants, Landcare Research, Auckland, New Zealand, IMI Culture collection of CABI Europe UK Centre, Egham, UK, $L C$ Working collection of Lei Cai, housed at CAS, China, MFLUCC Mae Fah Luang University Culture Collection, ChiangRai, Thailand, MTCC The Microbial Type Culture Collection and Gene Bank, Department of Biotechnology (DBT) and the Council of Scientific and Industrial Research (CSIR), Government of India, USJCC University of Sri Jayewardenepura culture collection, Department of Botany, University of Sri Jayewardenepura, Nugegoda, Sri Lanka. All the cultures in the table are ex-type cultures (T) except the isolates in the study (bold). Isolate codes and accession numbers in bold represents the isolates used in this study 

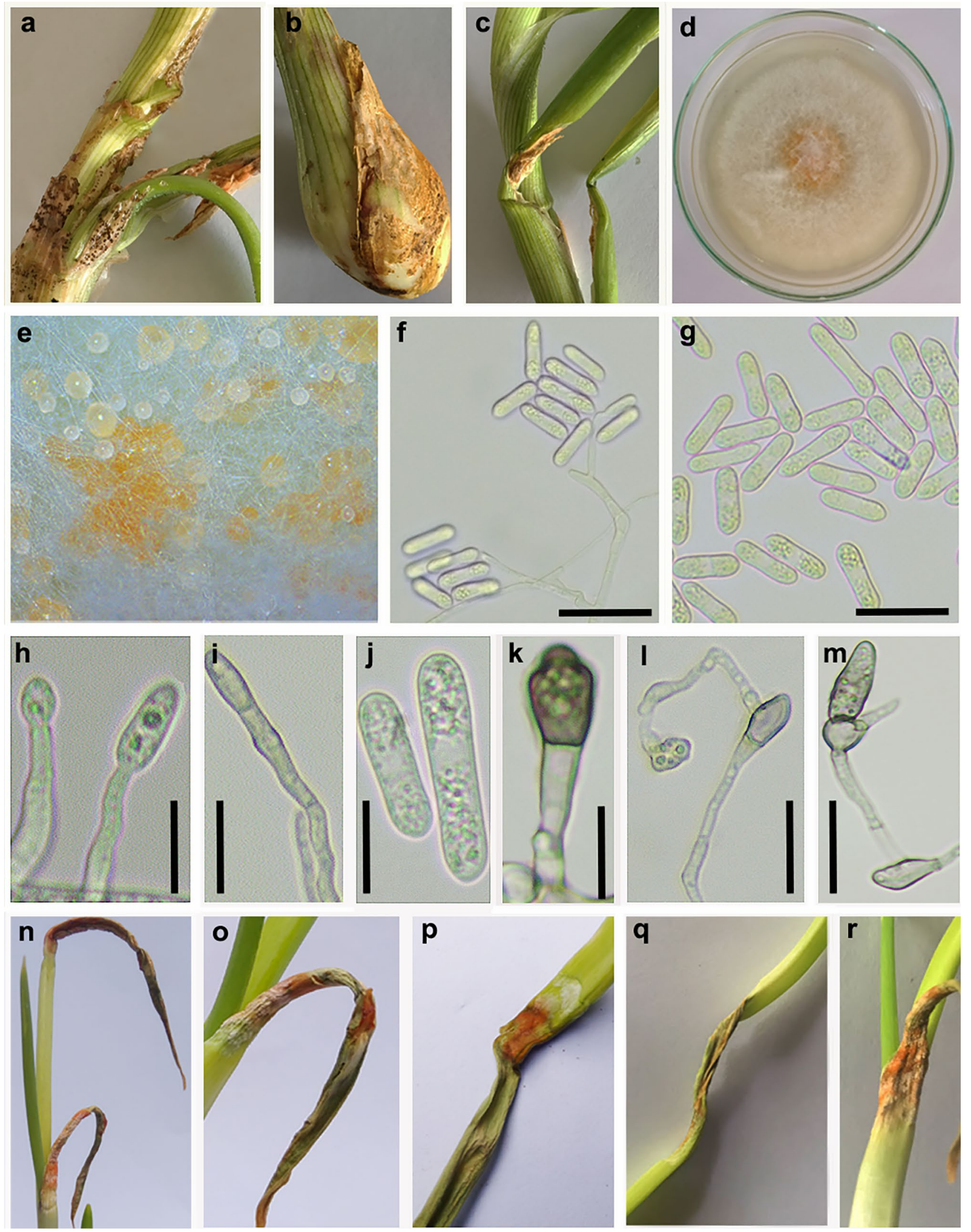

Fig. 1 Morphology of Colletotrichum siamense (a-c) Anthracnosetwister disease symptoms of onion plants d) Culture on PDA. e) Conidial masses on PDA. f,g) Conidia. h,i) Conidiophores. j) Conidia. $\mathbf{k - m}$ )
Appressoria produced on slide cultures of PDA. n-r) anthracnose-twister symptoms observed in pathogenicity testing. Scale bars: $f=33 \mu \mathrm{m}$; $g$ $\mathrm{i}=23 \mu \mathrm{m} ; \mathrm{j}, \mathrm{k}=10 \mu \mathrm{m} ; 1, \mathrm{~m}=5 \mu \mathrm{m}$ 


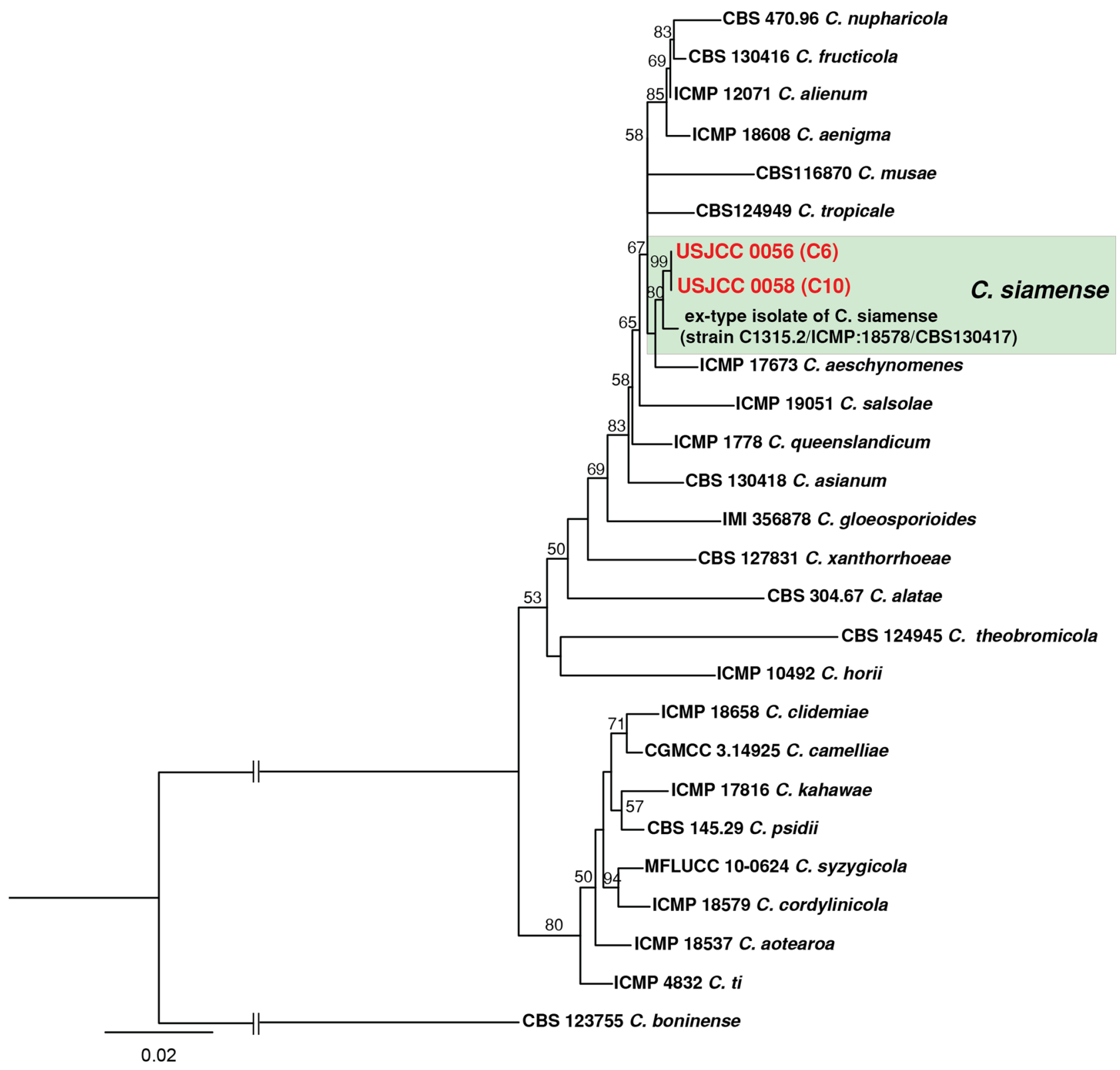

Fig. 2 Maximum Likelihood Phylogram generated using the combined analysis of ITS, GPDH and TUB2 for the Colletotrichum gloeosporioides species complex with representative isolates from each taxon. Isolates from this study are indicated in red. Ex-type isolates

primers and resulted DNA sequences were deposited in GenBank (Table 1). Individual and combined Maximum Likelihood (ML) gene trees based on the three gene regions (ITS, GPDH and TUB2) were estimated using the software RAxML 8.2.8 Black Box (Stamatakis et al. 2008) in the CIPRES Science Gateway platform (Miller et al. 2010). For the concatenated dataset, all free-modal parameters were are indicated in bold. The ML bootstrap values greater than 50\% are displayed above the branches. The tree is rooted with $C$. boninense (CBS 123755)

estimated by RAxML with an ML estimate of 25 per site rate categories. The concatenated dataset was partitioned by locus and the gaps were treated as missing data. The RAxML analysis utilised the GTRCAT model of nucleotide substitution with the additional options of modeling rate heterogeneity $(\mathrm{G})$ and proportion invariable sites (I). 
Pathogenicity tests were carried out using healthy onion plants grown in potting mixture under greenhouse conditions. Fungal isolates were inoculated in non-wounded plants using colonised agar plugs of $7.5 \mathrm{~mm}$ diameter with actively growing mycelia and by spraying of conidial suspension $\left(10^{5}-10^{7}\right.$ conidia/ml). Each method of inoculation consisted of three replicates and a control per each isolate. Controls were maintained by using non-colonised agar plugs and autoclaved distilled water. Plants were incubated at $25^{\circ} \mathrm{C}$.

Morphological observations revealed that the fungal colonies grown on PDA were flat with entire margin, white surface with an abundant cottony aerial mycelium, and orange conidial masses visible in concentric rings. Conidia measured were $13.2-20.1 \times 3.7-5.9 \mu \mathrm{m}$ $(\bar{x}=15.2 \pm 1.5 \times 4.7 \pm 0.6, n=30)$, unicellular, hyaline, aseptate, smooth-walled, cylindrical with rounded apex. Appressoria measured were $7.2-12.3 \times 3.1-6.8 \mu \mathrm{m}$ $(\bar{x}=9.1 \pm 2.2 \times 5.6 \pm 1.4, n=5)$, unicellular, brown, thickwalled, ellipsoidal to irregular. Conidiophores were hyaline, cylindrical to subcylindrical (Fig. 1). Based on the morphological features, the isolates were tentatively identified as a species belong in Colletotrichum gloeosporioides complex (Weir et al. 2012).

The BLASTn search of newly generated ITS sequences, against ex-type material revealed that the isolates C6 (Culture collection: USJCC 0056) (GenBank: MW440478) and C10 (Culture collection: USJCC 0058) (GenBank: MW444844) are $99.8 \%$ identical to the ex-type of Colletotrichum siamense strain C1315.2 (culture collection(s): ICMP:18,578/ CBS130417, GenBank: JX010171). The standard BLASTn search of newly generated GPDH sequences of C6 (GenBank: MZ803133) and C10 (GenBank: MZ803135) revealed $99.8 \%$ identity with $C$. siamense isolates LC 2876 (GenBank: KP703334) and YJMB27 (GenBank: MK963091). Similarly, the BLASTn analysis of newly generated TUB2 sequences of C6 (GenBank: MZ803137) and C10 (GenBank: MZ803138), are 99.8\% identical with $C$. siamense YJMB29.1 (GenBank: MK963154) and YJMB22.1 (GenBank: MK963153) isolates.

A ML phylogenetic tree generated based on the combined DNA sequence alignment of three gene regions (ITS, GPDH and TUB2) with ex-type species in C. gloeosporioides species complex revealed that the two new isolates (C6 and C 10) obtained in this study are conspecific with extype isolate of $C$. siamense (strain C1315.2/ ICMP:18578/ CBS130417) (Fig. 2).

Pathogenicity experiments resulted in the appearance of symptoms similar to original specimens, after $5 \mathrm{~d}$ of incubation. The control plants remained symptomless. Koch's postulates were completed by re-isolating the pathogen from symptom-bearing plants. $C$. siamense had been previously found affecting onion plants in Southwest India causing anthracnose (Chowdappa et al. 2015; Farr and Rossman 2021). To our knowledge, this is the first report of $C$. siamense affecting A. cepa in Sri Lanka. Further studies will be required to understand the epidemiology of this disease and foster disease management programs in Sri Lanka to avert potential outbreaks in future.

Acknowledgements We thank Dr. Lasanthi Jayathunge, Department of Biosystems Technology for providing additional specimens for this study. Himashi Ferdinandez is thanked for technical assistance. The use of trade, firm, or corporation names in this publication is for the information and convenience of the reader. Such use does not constitute an official endorsement or approval by the United States Department of Agriculture or any other affiliated institute of the authors. The USDA is an equal opportunity employer.

\section{Declarations}

Conflict of interests The author(s) declare no conflict of interest.

\section{References}

Alberto RT, Isip MF, Biagtan AR, Tagaca RC (2019) Disease risk map of anthracnose-twister of onion based on previous disease locations as a future predictors. Spat Inf Res 27:259-265. https://doi. org/10.1007/s41324-018-0229-4

Arnold AE, Lutzoni F (2007) Diversity and host range of foliar fungal endophytes: Are tropical leaves biodiversity hotspots? Ecology 88(3):541-549. https://doi.org/10.1890/05-1459

Choi YW, Hyde KD, Ho WH (1999) Single spore isolation of fungi. Fungal Diversity 3:29-38

Chowdappa P, Chethana CS, Pavani KV (2015) Colletotrichum siamense and $C$. truncatum are responsible for severe outbreaks of anthracnose on onion in southwest India. J plant pathol 97(1):7786. https://doi.org/10.4454/JPP.V97I1.015

Conn KE, Jeffrey SL, Rosenberger SA (2012) Onion Disease Guide. Seminis Vegetable Seeds, inc

Damm U, Woudenberg JHC, Cannon PF, Crous PW (2009) Colletotrichum species with curved conidia from herbaceous hosts. Fungal Diversity 39:45-87

DCS (2020) Extent and production of big onion in Yala season 2020. Statistical Abstracts. Department of Census and Statistics, Colombo, Sri Lanka. http://www.statistics.gov.lk/Resource/ en/Agriculture/Publications/Extent_and_production_of_Big_ Onion_2020_Yala.pdf. Accessed 23 March 2021

Farr DF, Rossman AY Fungal Databases. U.S. National Fungus Collections, ARS, USDA. https://nt.ars-grin.gov/fungaldatabases. Accessed 23 March 2021

Mishra RK, Jaiswal RK, Kumar D, Saabale PR, Singh A (2014) Management of major diseases and insect pests of onion and garlic: A comprehensive review. J Plant Breed Crop Sci 6(11):160 217. https://doi.org/10.5897/JPBCS2014.0467

O’Donnell K, Cigelnik E (1997) Two divergent intragenomic rDNA ITS2 types within a monophyletic lineage of the fungus Fusarium are nonorthologous. Mol Phylogenet Evol 7:103-116. https://doi. org/10.1006/mpev.1996.0376

Stamatakis A, Hoover P, Rougemont J (2008) A rapid bootstrap algorithm for the RAxML web servers. Syst Biol 57(5):758-771. https://doi.org/10.1080/10635150802429642

Miller MA, Pfeiffer W, Schwartz T (2010) Creating the CIPRES Science Gateway for inference of large phylogenetic trees. In: 
Gateway Computing Environments Workshop (GCE), 2010. Institute of Electrical and Electronics Engineers, New Orleans, LA, pp 1-8. https://doi.org/10.1109/GCE.2010.5676129

Templeton M, Rikkerink E, Solon S, Crowhurst R (1992) Cloning and molecular characterization of the glyceraldehyde-3-phosphate dehydrogenase-encoding gene and cDNA from the plant pathogenic fungus Glomerella cingulata. Gene 122(1):225-230. https:// doi.org/10.1016/0378-1119(92)90055-t
Weir BS, Johnston PR, Damm U (2012) The Colletotrichum gloeosporioides species complex. Stud Mycol 73:115-180. https:// doi.org/10.3114/sim0011

White TJ, Bruns T, Lee SJWT, Taylor JL et al (1990) Amplification and direct sequencing of fungal ribosomal RNA Genes for phylogenetics. PCR protocols: a guide to methods and applications 18(1):315-322. https://doi.org/10.1016/b978-0-12-372180-8. $50042-1$ 